\title{
Baseline Sarcopenia and Skeletal Muscle Loss During Chemotherapy Affect Survival Outcomes in Metastatic Gastric Cancer
}

\author{
KEIJI SUGIYAMA ${ }^{1}$, YUKIYA NARITA ${ }^{1}$, SEIICHIRO MITANI ${ }^{1}$, KAZUNORI HONDA $^{1}$, \\ TOSHIKI MASUISHI ${ }^{1}$, HIROYA TANIGUCHI ${ }^{1}$, SHIGENORI KADOWAKI $^{1}$, \\ TAKASHI URA ${ }^{1}$, MASASHI ANDO $^{1}$, MASAHIRO TAJIKA $^{2}$ and KEI MURO ${ }^{1}$ \\ Departments of ${ }^{1}$ Clinical Oncology and ${ }^{2}$ Endoscopy, Aichi Cancer Center Hospital, Nagoya, Japan
}

\begin{abstract}
Aim: To determine the association between sarcopenia and prognosis in patients with metastatic gastric cancer $(m G C)$ receiving chemotherapy. Patients and Methods: Our study retrospectively evaluated 231 consecutive Japanese patients with $m G C$ who commenced first-line chemotherapy at our Institution between January 2013 and December 2015. Muscle loss during chemotherapy was defined as a $\geq 10 \%$ reduction in the skeletal muscle index and was evaluated for its association with time to treatment failure (TTF) and overall survival (OS). Results: Of 118 patients, $89 \%$ had baseline sarcopenia and $31 \%$ developed muscle loss. Muscle loss was significantly associated with shorter TTF and OS and was an independent prognostic factor for both these parameters; poor performance status and poorer differentiation on histology were also significant predictors of shorter OS. However, muscle loss was not significantly associated with increased grade 3 or higher toxicities. Conclusion: Muscle loss during chemotherapy negatively affected survival among patients with $m G C$.
\end{abstract}

Gastric cancer is the third leading cause of cancer-related death and is an especially prevalent disease in east Asia (1). Although systemic chemotherapy has improved the outcomes of patients with metastatic gastric cancer (mGC) compared with best supportive care alone, outcomes remain poor, with median survival times of approximately 10-14 months $(2,3)$. In this context, there is growing evidence that

Correspondence to: Yukiya Narita, Department of Clinical Oncology, Aichi Cancer Center Hospital, 1-1 Kanokoden, Chikusaku, Nagoya, Aichi 464-8681, Japan. Tel: +81 527626111, Fax: +81 527528390, e-mail: yukiya.narita@aichi-cc.jp

Key Words: Chemotherapy, gastric cancer, prognostic factor, sarcopenia, skeletal muscle loss. depletion of muscle volume (sarcopenia) negatively affects oncological outcomes. The mechanisms underlying cachexia, hypercatabolism, and sarcopenia are complex and include aging, low physical activity, malnutrition, anorexia, and hyperinflammation mediated by humoral (e.g. inflammatory cytokines) or neural factors (4).

Abnormal metabolism is a common phenomenon in many types of advanced cancer, including gastric cancer, and mGC frequently involves cachexia or sarcopenia $(5,6)$. In addition, sarcopenia can be induced by highly toxic chemotherapeutic agents (e.g. capecitabine or 5-fluorouracil for metastatic colorectal cancer) $(7,8)$. The main treatment for $\mathrm{mGC}$ is systemic chemotherapy. Although it is unclear whether sarcopenia affects survival among patients with mGC who receive systemic chemotherapy, sarcopenia is reportedly associated with poor overall survival (OS) in those with resectable gastric cancer (9), colorectal cancer (10), hepatocellular carcinoma (11), and oesophageal cancer (12). Interestingly, previous studies have indicated that muscle loss during chemotherapy, rather than baseline sarcopenia, independently predicts poor OS among patients with metastatic colorectal cancer $(13,14)$. Moreover, the outcomes of $\mathrm{mGC}$ are affected by various clinical factors, including poor performance status, multiple metastatic sites, peritoneal metastasis, bone metastasis, liver metastasis, elevated alkaline phosphatase (ALP), and elevated lactate dehydrogenase $(\mathrm{LDH})(15,16)$. This study aimed to assess whether sarcopenia and muscle loss can serve as factors predictive of survival outcomes and toxicity among patients with $\mathrm{mGC}$ who receive chemotherapy.

\section{Patients and Methods}

Study population. Our study retrospectively evaluated 231 consecutive Japanese patients with $\mathrm{mGC}$ who commenced first-line platinum-based chemotherapy at our Institution between January 2013 and December 2015. The inclusion criteria were: age $>18$ years, histologically confirmed mGC (adenocarcinoma), treatment 
using fluoropyrimidine plus a platinum agent (cisplatin or oxaliplatin), an Eastern Cooperative Oncology Group performance status (PS) score of 0-2, adequate organ function, and available abdominal computed tomographic (CT) data acquired $\leq 30$ days before the first chemotherapy dosing (baseline analysis) and $>8$ weeks (56-144 days) after initiating chemotherapy. To homogenize the cohort, patients who received non-platinum-based regimens were excluded. The study was approved by the Aichi Cancer Center Hospital Institutional Review Board (no. 2013-3-103).

Outcomes. The overall response rate (ORR) was evaluated using version 1.1 of the Response Evaluation Criteria in Solid Tumours (17), and adverse events were evaluated using version 4.0 of the Common Terminology Criteria for Adverse Events (18). Treatment exposure was calculated as the relative dose intensity. The modified Glasgow prognostic score (mGPS) was calculated based on a score of 2 for patients with elevated serum C-reactive protein (CRP) level $(>0.5 \mathrm{mg} / \mathrm{dl})$ and hypoalbuminemia $(\leq 3.5 \mathrm{~g} / \mathrm{dI})$, a score of 1 for a single abnormal value, and a score of 0 for no abnormal values (19). Time to treatment failure (TTF) was calculated from the date of the first chemotherapy dosing to the date of treatment discontinuation for any reason. OS was calculated from the date of first chemotherapy administration to the date of death from any cause or the last follow-up visit.

Measurement of skeletal muscle volume and skeletal muscle loss. Muscle area at the third lumbar vertebra (L3) is a standard skeletal landmark that correlates with whole-body muscle volume (20). Therefore, the cross-sectional skeletal muscle area at L3 was measured $\left(\mathrm{cm}^{2}\right)$ using routine abdominal CT data and the Volume Analyzer Synapse Vincent 3 image analysis system (Fujifilm Medical, Tokyo, Japan). Skeletal muscle was identified and quantified using Hounsfield units (HU) with thresholds of $-29 \mathrm{HU}$ to $150 \mathrm{HU}$. The skeletal muscle area at L3 was normalized using the skeletal muscle index (SMI), which is calculated as the crosssectional muscle area $\left(\mathrm{cm}^{2}\right)$ at L3 divided by height squared $\left(\mathrm{m}^{2}\right)$ $(11,12)$. Sarcopenia at baseline was defined according to Prado et al.'s criteria as an SMI $\leq 53.4 \mathrm{~cm}^{2} / \mathrm{m}^{2}$ for men and $\leq 38.5 \mathrm{~cm}^{2} / \mathrm{m}^{2}$ for women (21). Muscle loss was defined as a decrease in SMI of more than $10 \%$ at the first evaluation relative to baseline because the cut-off value for the lowest tertile was approximately $10 \%$.

Data analysis. The patients were grouped according to whether they had sarcopenia at baseline and whether they developed muscle loss. The relationships of clinicopathological factors with sarcopenia and muscle loss were evaluated using the Chi-square test or Fisher's exact test. Survival curves were estimated using the Kaplan-Meier method and compared using the log-rank test. Univariate and multivariate Cox regression analyses were performed to determine whether baseline sarcopenia or muscle loss predicted TTF or OS, and variables with $p \leq 0.1$ on univariate analyses were subjected to multivariate analyses. Two-sided p-values of 0.05 or less were considered statistically significant. All statistical analyses were performed using EZR (The R Foundation for Statistical Computing, Vienna, Austria) (22).

\section{Results}

Patient characteristics. The present study included 118 patients (49.7\% of potentially eligible patients) after excluding
Patients with $\mathbf{m G C}$ who received first-line CTx $(n=231)$ between January 2013 and December 2015

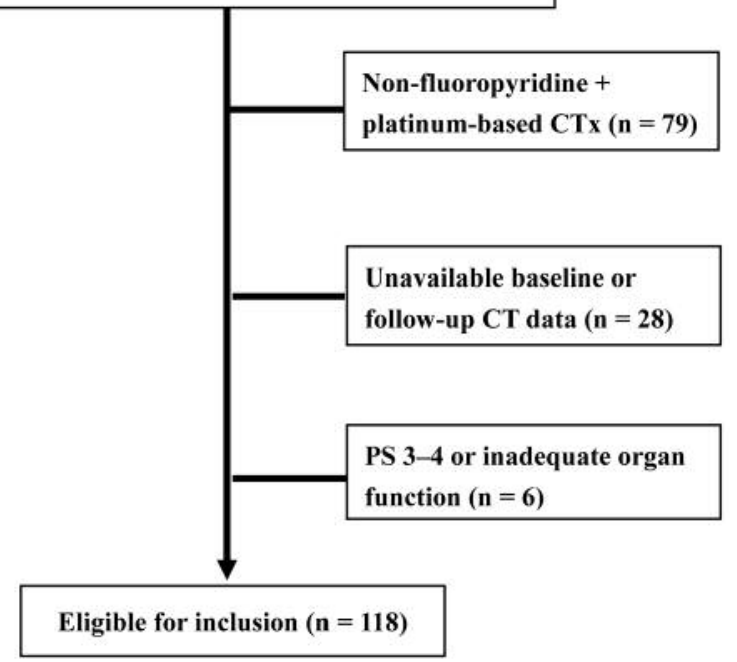

Figure 1. Study flow chart. CT, Computed tomography; CTx, chemotherapy; $m G C$, metastatic gastric cancer; PS, performance status.

79 who were treated using non-platinum-based chemotherapy, 28 patients without available CT data, and six patients with poor PS or inadequate organ function (Figure 1). The median follow-up time was 14.3 months (range=2.5-39.2 months), within which treatment failure occurred in all patients. The median OS was 17.5 months $[95 \%$ confidence interval (CI)=13.6-20 months], while the median TTF was 7.3 months (95\% CI=6.3-8.6 months). The patients' characteristics are shown in Table I; 105 patients $(89 \%)$ had sarcopenia at baseline based on Prado et al.'s criteria and 37 patients (31\%) developed muscle loss. The latter was significantly associated with increased ALP, LDH, and CRP levels compared with baseline. Marked differences were also observed according to muscle loss status in the neutrophil-to-lymphocyte ratio (NLR; $<3$ vs. $\geq 3, p=0.05)$ and mGPS $(p=0.06)$. There was minimal change in body mass index between the baseline evaluation and the first treatment evaluation; the change in SMI was slightly greater than that for body mass index (Table II).

Treatment outcomes. The ORR values were $68 \%$ and $55 \%$ $(p=0.49)$ for the sarcopenic and non-sarcopenic groups, respectively, and $65 \%$ and $68 \%(p>0.99)$ for groups with and without muscle loss, respectively. The effect of variation in time to follow-up CT on OS and TTF was evaluated. Patients were divided into three groups based on the time to followup CT (group 1=56-68 days, group 2=69-92 days, and group $3=94-144$ days). OS did not vary significantly among the three groups [group 1: $\mathrm{N}=39$, median $\mathrm{OS}=20.2 \quad(95 \%$ 
Table I. Patient characteristics.

\begin{tabular}{|c|c|c|c|c|c|c|c|}
\hline & $\begin{array}{c}\text { All } \\
(\mathrm{n}=118)\end{array}$ & $\begin{array}{l}\text { Sarcopenia } \\
\quad(\mathrm{n}=105)\end{array}$ & $\begin{array}{c}\text { No sarcopenia } \\
\quad(\mathrm{n}=13)\end{array}$ & $p$-Value & $\begin{array}{l}\text { Muscle loss } \\
\quad(\mathrm{n}=37)\end{array}$ & $\begin{array}{l}\text { No muscle loss } \\
\qquad(\mathrm{n}=81)\end{array}$ & $p$-Value \\
\hline \multicolumn{8}{|l|}{ Age, years } \\
\hline Median (range) & $64(27-84)$ & $64(27-84)$ & $57(47-79)$ & - & $64(27-79)$ & $64(30-84)$ & - \\
\hline \multicolumn{8}{|l|}{ Gender, $\%$} \\
\hline Male/female & $59 / 41$ & $61 / 39$ & $43 / 57$ & 0.37 & $64 / 36$ & $56 / 44$ & 0.42 \\
\hline \multicolumn{8}{|l|}{ ECOG PS } \\
\hline $0 / 1 / 2$ & $38 / 53 / 9$ & $40 / 50 / 10$ & $31 / 62 / 7$ & 0.82 & $30 / 54 / 16$ & $43 / 50 / 7$ & 0.12 \\
\hline \multicolumn{8}{|l|}{ BMI $\left(\mathrm{kg} / \mathrm{m}^{2}\right), \%$} \\
\hline$\leq 18.5 / 18.5-25 />25$ & $16 / 70 / 14$ & $23 / 70 / 7$ & $0 / 38 / 62$ & $\leq 0.001$ & $17 / 68 / 15$ & $19 / 70 / 11$ & 0.83 \\
\hline \multicolumn{8}{|l|}{ Histology,\% } \\
\hline Diff/undiff & $25 / 75$ & $74 / 26$ & $84 / 16$ & 0.51 & $13 / 87$ & $30 / 70$ & 0.09 \\
\hline \multicolumn{8}{|l|}{ HER2 status, $\%$} \\
\hline Pos/neg/NA & $25 / 74 / 1$ & $74 / 26$ & $84 / 16$ & 0.56 & $32 / 68 / 0$ & $23 / 76 / 1$ & 0.35 \\
\hline \multicolumn{8}{|c|}{ No. of metastatic sites, $\%$} \\
\hline $1 / \geq 2$ & $53 / 47$ & $54 / 46$ & $46 / 54$ & 0.79 & $47 / 53$ & $55 / 45$ & 0.61 \\
\hline \multicolumn{8}{|l|}{ Metastasis location, $\%$} \\
\hline Peritoneum & 59 & $41 / 59$ & $38 / 62$ & 0.92 & 62 & 58 & 0.82 \\
\hline Liver & 22 & $75 / 25$ & $92 / 8$ & 0.30 & 29 & 20 & 0.33 \\
\hline \multicolumn{8}{|l|}{ Regimen,\% } \\
\hline Cis/ox-based & $78 / 22$ & $78 / 22$ & $77 / 23$ & $>0.99$ & $80 / 20$ & $73 / 27$ & 0.51 \\
\hline \multicolumn{8}{|l|}{$\operatorname{ALP}(\mathrm{U} / \mathrm{l}), \%$} \\
\hline$<\mathrm{ULN} / \geq \mathrm{ULN}$ & $75 / 25$ & $73 / 27$ & $84 / 16$ & 0.58 & $59 / 41$ & $76 / 24$ & 0.02 \\
\hline \multicolumn{8}{|l|}{$\mathrm{LDH}(\mathrm{U} / \mathrm{l}), \%$} \\
\hline$<\mathrm{ULN} / \geq \mathrm{ULN}$ & $85 / 15$ & $84 / 16$ & $92 / 8$ & 0.69 & $73 / 27$ & $90 / 10$ & 0.03 \\
\hline \multicolumn{8}{|l|}{ NLR,$\%$} \\
\hline$<3 / \geq 3$ & $44 / 56$ & $46 / 54$ & $23 / 77$ & 0.18 & $30 / 70$ & $51 / 49$ & 0.05 \\
\hline \multicolumn{8}{|l|}{ mGPS $\%$} \\
\hline $0 / 1 / 2$ & $50 / 27 / 23$ & $49 / 28 / 23$ & $62 / 15 / 23$ & 0.56 & $41 / 35 / 24$ & $63 / 25 / 12$ & 0.06 \\
\hline
\end{tabular}

Muscle loss refers to muscle loss during chemotherapy. ECOG PS, Eastern Cooperative Oncology Group performance status; BMI, body mass index; Diff, differentiated; undiff, undifferentiated; HER2, human epidermal growth factor 2; Pos, positive; NA, not assessed; neg, negative; Cis, cisplatin; ox, oxaliplatin; ALP, alkaline phosphatase; ULN, upper limit of normal; LDH, lactate dehydrogenase; NLR, neutrophil-to-lymphocyte ratio; mGPS, modified Glasgow prognostic score.

Table II. Change in skeletal muscle index and body mass index.

\begin{tabular}{llcc}
\hline & \multicolumn{3}{c}{ Time point } \\
\cline { 2 - 3 } Parameter & At baseline, mean (SD) & At follow-up, mean (SD) & Change \\
\hline Skeletal muscle index $\left(\mathrm{cm}^{2} / \mathrm{m}^{2}\right)$ & & $36.4(8.05)$ & $-7 \%$ \\
$\quad$ All & $39.0(8.02)$ & $39.6(7.84)$ & $-7 \%$ \\
Male & $42.5(7.55)$ & $31.7(5.76)$ & $-7 \%$ \\
$\quad$ Female & $33.9(5.56)$ & $20.6(3.18)$ & $-2 \%$ \\
Body mass index $\left(\mathrm{kg} / \mathrm{m}^{2}\right)$ & & $21.2(3.07)$ & $-2 \%$ \\
All & $21.1(3.24)$ & $20.0(3.22)$ & $-2 \%$ \\
Male & $21.6(2.89)$ & & \\
Female & $20.3(3.55)$ & & \\
\hline
\end{tabular}

$\mathrm{SD}$, Standard deviation.

$\mathrm{CI}=13.6-30.6)$ months; group 2: $\mathrm{N}=40$, median $\mathrm{OS}=12.4$ (95\% CI=9.8-20.2) months; and group 3: $\mathrm{N}=39$, median $\mathrm{OS}=17.5$ (95\% CI=11.9-22.5) months; $p=0.15$ (log-rank test)]. TTF was not significantly altered based on time to follow-up CT [group 1: $\mathrm{N}=39$, median $\mathrm{TTF}=8.2(95 \%$ $\mathrm{CI}=6.3-9.3)$ months; group 2: $\mathrm{N}=40$, median $\mathrm{TTF}=7.0(95 \%$ $\mathrm{CI}=5.93-9.26)$ months; and group 3: $\mathrm{N}=39$, median $\mathrm{TTF}=7.2$ (95\% CI=3.7-9.1) months; $p=0.48$ (log-rank test)]. 

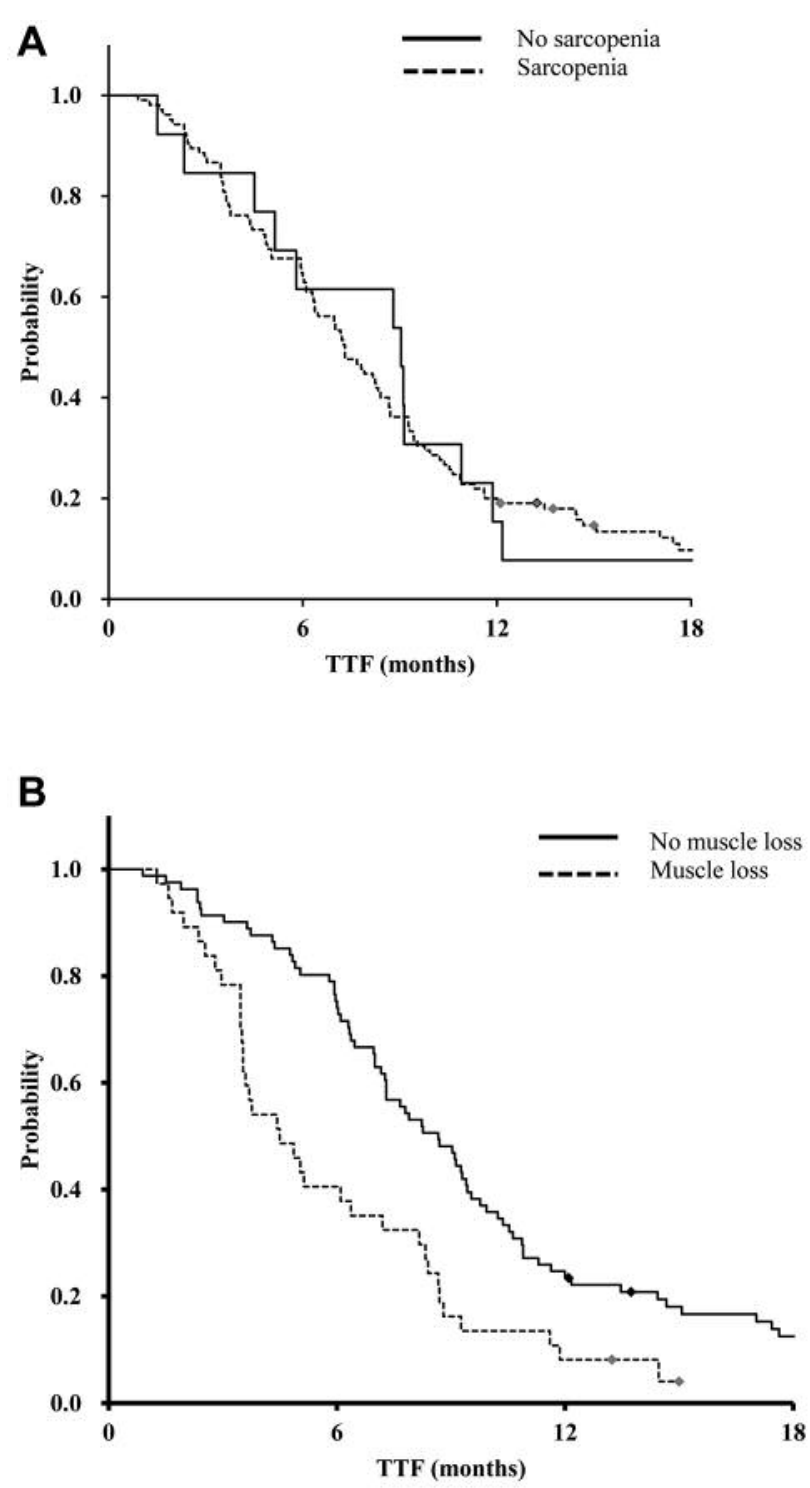
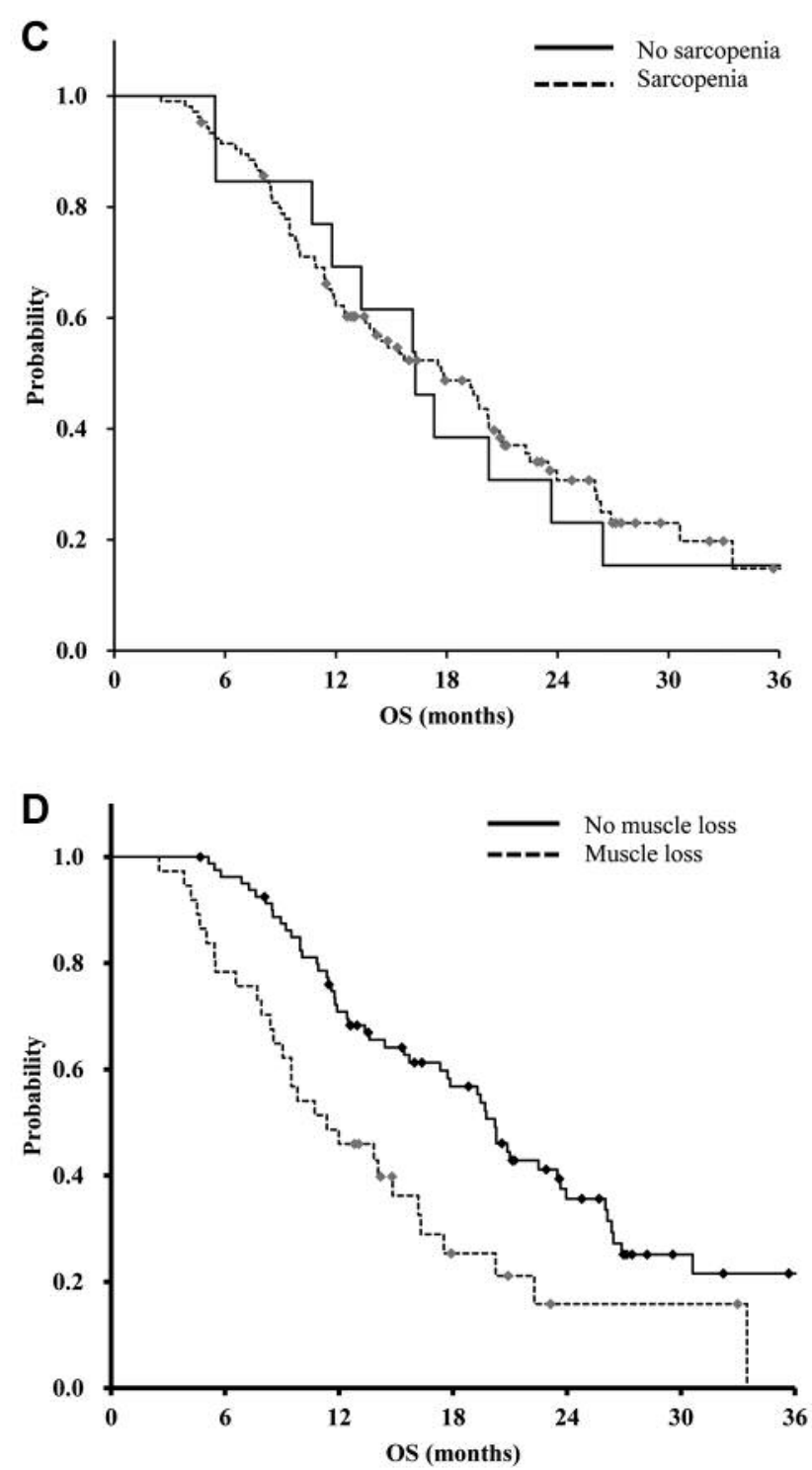

Figure 2. Kaplan-Meier survival curves for time to treatment failure (TTF; A and B) and overall survival (OS; C and D) according to sarcopenia status and muscle loss.

To calculate the cut-off value for muscle loss, patients were divided into three groups by percentage change in SMI after chemotherapy (tertile $1: 61.4-89.7 \%$, tertile $2: 90.0$ 96.9\%, and tertile 3: 96.9-126.3\%) (14). The cut-off for muscle loss was based on the lowest tertile (approximately $10 \%)$.

Sarcopenia was not associated with TTF [hazard ratio $(\mathrm{HR})=1.11,95 \% \mathrm{CI}=0.61-2.04, p=0.71]$ or $\mathrm{OS}(\mathrm{HR}=0.94$, 95\% CI=0.50-1.79, $p=0.87$ ) (Figure 2). However, muscle loss was significantly associated with both shorter TTF (muscle loss vs. non-muscle loss: 4.5 vs. 8.6 months, $\mathrm{HR}=2.08,95 \% \mathrm{CI}=1.37-3.15, p \leq 0.001)$ and shorter OS (11.3 vs. 20.2 months, $\mathrm{HR}=2.10,95 \% \mathrm{CI}=1.32-3.33, p=0.001$ ) (Figure 2). Univariate analyses revealed that poor TTF was associated with muscle loss $(p \leq 0.001)$, elevated LDH $(p=0.03)$, poor mGPS (0-1 vs. $2, p=0.03)$, and poorer differentiation $(p=0.01)$. Only muscle loss independently predicted TTF on multivariate analysis $(p=0.01)$. Univariate analyses also revealed that poor OS was associated with muscle loss $(p=0.01)$, poor PS $(p=0.02)$, poorer differentiation $(p \leq 0.001)$, human epidermal growth factor 2 expression $(p=0.04)$, and peritoneal metastasis $(p=0.03)$; multivariate analyses revealed that poor OS was independently predicted by muscle loss $(p=0.01)$, poor PS 
Table III. Univariate and multivariate analyses of factors associated with time to treatment failure (TTF) and overall survival (OS).

\begin{tabular}{|c|c|c|c|c|c|c|c|c|c|}
\hline \multirow[b]{3}{*}{ Factor } & \multirow[b]{3}{*}{ Comparison } & \multicolumn{4}{|c|}{ TTF } & \multicolumn{4}{|c|}{ OS } \\
\hline & & \multicolumn{2}{|c|}{ Univariate analysis } & \multicolumn{2}{|c|}{ Multivariate analysis } & \multicolumn{2}{|c|}{ Univariate analysis } & \multicolumn{2}{|c|}{ Multivariate analysis } \\
\hline & & $\mathrm{HR}(95 \% \mathrm{CI})$ & $p$-Value & $\mathrm{HR}(95 \% \mathrm{CI})$ & $p$-Value & $\operatorname{HR}(95 \% \mathrm{CI})$ & $p$-Value & $\mathrm{HR}(95 \% \mathrm{CI})$ & $p$-Value \\
\hline Baseline status & $\begin{array}{l}\text { Sarcopenia } v s \text {. } \\
\text { no sarcopenia }\end{array}$ & $1.18(0.61-2.04)$ & 0.71 & & & $0.94(0.50-1.79)$ & 0.87 & $0.94(0.50-1.79)$ & 0.87 \\
\hline Skeletal muscle loss & $\begin{array}{l}\text { Muscle loss vs. } \\
\text { no muscle loss }\end{array}$ & $2.08(1.37-3.15)$ & $\leq 0.001$ & $1.96(1.28-3.00)$ & 0.01 & $2.10(1.32-3.33)$ & 0.01 & $2.10(1.32-3.33)$ & 0.01 \\
\hline ECOG PS & $1-2 v s .0$ & $1.28(0.87-1.89)$ & 0.20 & $1.31(0.88-1.95)$ & 0.17 & $2.08(1.30-3.35)$ & 0.02 & $2.08(1.30-3.35)$ & 0.02 \\
\hline Gastrectomy & Yes $v s$. no & $1.39(0.93-2.09)$ & 0.11 & & & $1.18(0.74-1.88)$ & 0.47 & & \\
\hline Histology & Undiff $v s$. diff & $1.69(1.09-2.64)$ & 0.01 & $1.53(0.97-2.40)$ & 0.06 & $3.37(1.81-626)$ & $\leq 0.001$ & $3.37(1.81-626)$ & $\leq 0.001$ \\
\hline HER2 status & Neg vs. pos & $0.76(0.49-1.19)$ & 0.23 & & & $0.56(0.32-0.98)$ & 0.04 & $0.56(0.32-0.98)$ & 0.04 \\
\hline Metastatic sites & $\geq 2$ vs. 1 & $1.16(0.79-1.69)$ & 0.43 & & & $0.91(0.58-1.42)$ & 0.69 & & \\
\hline Peritoneal metastasis & Yes $v s$. no & $1.21(0.82-1.78)$ & 0.31 & & & $1.62(1.03-2.55)$ & 0.03 & $1.62(1.03-2.55)$ & 0.03 \\
\hline ALP (U/1) & $\geq \mathrm{ULN} v s .<\mathrm{ULN}$ & $1.01(0.65-1.56)$ & 0.96 & & & $1.27(0.76-2.10)$ & 0.34 & & \\
\hline LDH (U/l) & $\geq \mathrm{ULN} v s .<\mathrm{ULN}$ & $1.74(1.03-2.95)$ & 0.03 & & & $1.55(0.87-2.77)$ & 0.13 & & \\
\hline NLR & $\geq 3 v s .<3$ & $1.19(0.81-1.73)$ & 0.37 & & & $1.22(0.78-1.91)$ & 0.36 & & \\
\hline mGPS & 2 vs. 0-1 & $1.60(1.02-2.49)$ & 0.03 & & & $1.29(0.78-2.15)$ & 0.31 & & \\
\hline
\end{tabular}

HR: Hazard ratio; CI, confidence interval; Sarco, sarcopenia; ECOG PS, Eastern Cooperative Oncology Group performance status; Diff, differentiated; undiff, undifferentiated; HER2, human epidermal growth factor 2; Pos, positive; neg, negative; ALP, alkaline phosphatase; ULN, upper limit of normal; LDH, lactate dehydrogenase; NLR, neutrophil-to-lymphocyte ratio; mGPS, modified Glasgow prognostic score.

$(p=0.01)$, and poorer differentiation $(p=0.001)$ (Table III). Second-line chemotherapy was administered to the sarcopenic and non-sarcopenic groups in similar proportions (77\% and $76 \%$, respectively; $p>0.99)$. Similarly, a comparison of the groups with and without muscle loss revealed similar proportions of second-line $(78 \%$ and $70 \%$, respectively; $p=0.89)$, third-line ( $40 \%$ and $44 \%$, respectively; $p=0.84)$, and fourth-line or later chemotherapies (16\% and $22 \%$, respectively; $p=0.61)$. No significant inter-group differences were observed in the relative dose intensities of S-1 plus cisplatin, capecitabine plus cisplatin, or S-1 plus oxaliplatin (Table IV).

Adverse events. No significant differences were observed in the occurrence of grade 3 or higher haematological and nonhaematological toxicities between the sarcopenic and nonsarcopenic groups or between the groups with and without muscle loss (Table V). All-grade anorexia was significantly more common in the group with muscle loss than in that without muscle loss $(p=0.02)$.

\section{Discussion}

To the best of our knowledge, this is the first study to demonstrate a relationship between skeletal muscle depletion and outcomes among patients with $\mathrm{mGC}$ who received systemic chemotherapy, with several interesting findings. Firstly, the development of muscle loss was significantly and
Table IV. Treatment exposure for each regimen given as median relative dose intensity (range).

\begin{tabular}{lccc}
\hline $\begin{array}{l}\text { Regimen median } \\
\text { (range) }\end{array}$ & $\begin{array}{c}\text { Muscle } \\
\text { loss }\end{array}$ & $\begin{array}{c}\text { No muscle } \\
\text { loss }\end{array}$ & $p$-Value \\
\hline SP & $\mathrm{n}=13$ & $\mathrm{n}=48$ & \\
S-1 & $90 \%(56-100 \%)$ & $94 \%(72-100 \%)$ & 0.13 \\
Cisplatin & $81(49-100 \%)$ & $82(47-102 \%)$ & 0.73 \\
XP & $\mathrm{n}=10$ & $\mathrm{n}=13$ & \\
Capecitabine & $89 \%(77-100 \%)$ & $85 \%(35-100 \%)$ & 0.14 \\
Cisplatin & $76(55-100 \%)$ & $67 \%(50-103 \%)$ & 0.14 \\
SOX & $\mathrm{n}=6$ & $\mathrm{n}=12$ & \\
S-1 & $83 \%(80-100 \%)$ & $85 \%(80-100 \%)$ & 0.35 \\
Oxaliplatin & $91 \%(59-100 \%)$ & $92 \%(59-103 \%)$ & 0.76 \\
\hline
\end{tabular}

Muscle loss, Muscle loss during chemotherapy. $p$-Values were obtained using Student's $t$-test.

negatively associated with both TTF and OS. Secondly, sarcopenia at baseline was not associated with survival outcomes. Third, there were no significant differences between the sarcopenic and non-sarcopenic groups nor between the groups with and without muscle loss in terms of best tumour response, treatment-related toxicities (except anorexia), and the proportion of patients who received subsequent chemotherapy. These findings suggest that physicians should carefully consider both their patients' baseline body weight and SMI, as well as any changes in 
Table V. Adverse events experienced by patients during chemotherapy according to sarcopenia and muscle loss.

\begin{tabular}{|c|c|c|c|c|c|c|c|c|c|c|}
\hline \multirow[b]{2}{*}{ Adverse event } & \multicolumn{2}{|c|}{$\begin{array}{l}\text { Sarcopenia } \\
(\mathrm{n}=105)\end{array}$} & \multicolumn{2}{|c|}{$\begin{array}{l}\text { No sarcopenia } \\
\quad(n=13)\end{array}$} & \multirow[t]{2}{*}{$p$-Value } & \multicolumn{2}{|c|}{$\begin{array}{l}\text { Muscle loss } \\
\quad(\mathrm{n}=37)\end{array}$} & \multicolumn{2}{|c|}{$\begin{array}{l}\text { No muscle loss } \\
\quad(\mathrm{n}=81)\end{array}$} & \multirow[t]{2}{*}{$p$-Value } \\
\hline & All & Grade 3-4 & All & Grade 3-4 & & All & Grade 3-4 & All & Grade 3-4 & \\
\hline Neutropenia & $55 \%$ & $29 \%$ & $61 \%$ & $46 \%$ & 0.89 & $54 \%$ & $35 \%$ & $56 \%$ & $29 \%$ & 0.93 \\
\hline Anaemia & $92 \%$ & $11 \%$ & $100 \%$ & $30 \%$ & 0.65 & $100 \%$ & $13 \%$ & $90 \%$ & $13 \%$ & 0.11 \\
\hline Thrombocytopenia & $40 \%$ & $6 \%$ & $61 \%$ & $7 \%$ & 0.26 & $51 \%$ & $8 \%$ & $39 \%$ & $6 \%$ & 0.31 \\
\hline Nausea & $58 \%$ & $4 \%$ & $61 \%$ & $0 \%$ & $>0.99$ & $62 \%$ & $5 \%$ & $55 \%$ & $3 \%$ & 0.45 \\
\hline Diarrhoea & $21 \%$ & $3 \%$ & $38 \%$ & $0 \%$ & 0.32 & $29 \%$ & $16 \%$ & $20 \%$ & $8 \%$ & 0.42 \\
\hline Fatigue & $33 \%$ & $3 \%$ & $38 \%$ & $0 \%$ & 0.95 & $35 \%$ & $2 \%$ & $33 \%$ & $3 \%$ & $>0.99$ \\
\hline Anorexia & $67 \%$ & $8 \%$ & $53 \%$ & $0 \%$ & 0.65 & $81 \%$ & $8 \%$ & $59 \%$ & $3 \%$ & 0.02 \\
\hline Mucositis & $20 \%$ & $0 \%$ & $15 \%$ & $0 \%$ & 0.98 & $21 \%$ & 0 & $18 \%$ & $0 \%$ & 0.88 \\
\hline Febrile neutropenia & $4 \%$ & $4 \%$ & - & $0 \%$ & 0.72 & - & $8 \%$ & - & $2 \%$ & 0.23 \\
\hline
\end{tabular}

Muscle loss, Muscle loss during chemotherapy. $p$-Values were calculated using the Chi-square test and comparing all events.

these variables during therapy. Moreover, muscle loss was significantly or marginally associated with high baseline values of $\operatorname{ALP}(p=0.02), \operatorname{LDH}(p=0.03), \operatorname{NLR}(p=0.05)$, and mGPS $(p=0.06)$, which are known markers of tumour burden or inflammation in patients with cancer. Hence, a high tumour burden or hyperinflammatory state may accelerate muscle loss and lead to poor outcomes.

In the present study, most patients with mGC had sarcopenia at baseline (89\%), although Prado et al.'s original cut-off value for diagnosing sarcopenia was determined using data from Western patients (21). Therefore, their criteria may have been too restrictive for Asian patients with $\mathrm{mGC}$, who may require modified population-specific benchmarks. Nevertheless, we failed to identify an optimal cut-off value for baseline sarcopenia that is predictive of poor outcomes despite evaluating several such values (data not shown). It is, therefore, possible that baseline sarcopenia has no impact on patient outcomes; indeed, previous studies have also shown a high prevalence of sarcopenia in patients with gastric cancer undergoing chemotherapy or surgery, but no association between sarcopenia and survival or postoperative complications $(23,24)$.

The present study revealed that muscle loss was an independent predictor of progressive disease (i.e. TTF) and mortality (i.e. OS) among patients with $\mathrm{mGC}$. It is interesting that muscle loss, but not baseline sarcopenia, was able to predict these outcomes, although using Prado et al.'s cut-off values for sarcopenia may explain this phenomenon. Notably, however, previous studies also found that muscle loss, but not baseline sarcopenia, was associated with poor OS among patients with metastatic colorectal cancer $(13,14)$.

The time to follow-up CT did not significantly affect OS or TTF. Although we did not evaluate muscle loss directly in relation to time to follow-up CT, the insignificant impact on OS and TTF showed that time to follow-up was not an influencing factor for prognosis. Although group 1 showed slightly better prognosis in terms of OS, the prognosis of group 2 was worse than that of group 3, suggesting that these changes were independent of time to follow-up CT. Further studies are required to evaluate the relationship between muscle loss and time to follow-up CT.

There were no significant differences between the groups with and without muscle loss in terms of best tumour response, treatment-related toxicities (except anorexia), chemosensitivity, or treatment exposure (first and subsequent lines). These findings suggest that the depletion of muscle volume (muscle loss) was accelerated independently of the efficacy of chemotherapy, although patients with muscle loss had a significantly higher prevalence of anorexia than those without $(p=0.02)$. Thus, low-grade anorexia may still be a crucial occurrence in patients with mGC who receive chemotherapy. Various approaches have been attempted to prevent cancer-related sarcopenia or cachexia, such as administration of corticosteroids (25), anabolic or sex hormones $(26,27)$, non-steroidal anti-inflammatory drugs (28), antibodies targeting inflammatory cytokines (29), immunomodulatory drugs (thalidomide) (30), and parenteral nutrition; however, these approaches have been unsuccessful. New classes of treatments, such as anamorelin (a ghrelin analogue) (31) and selective androgen receptor modulators $(32,33)$, may hold greater promise.

Our study had several limitations. Firstly, it was of a single-centre retrospective design. Secondly, muscle loss was determined after chemotherapy initiation, which carries the risk of lead-time bias. Nevertheless, we performed landmark analysis to address this issue and defined time 
zero as 120 days after the first chemotherapy dosing (i.e. at the first CT evaluation), which produced greater confidence that the group without muscle loss indeed had significantly better outcomes than that with muscle loss in terms of both TTF $(p=0.04)$ and OS $(p=0.002)$. The fact that muscle loss was observed in a subset of the study population $(n=37)$, but not in the entire cohort, highlights the fact that muscle loss is not a simple manifestation of disease progression, rather, it carries clinical relevance. A third limitation is the heterogeneous chemotherapy regimens used (i.e. cisplatin $v s$. oxaliplatin, multiple types of fluoropyrimidines, S-1 or capecitabine, doublet $v s$. triplet, and fluoropyrimidine plus platinum with or without taxane), which could lead to differing extents of muscle loss owing to the different routes of disease progression. Finally, we only used muscle volume as an indicator of muscle loss, although this is consistent with several previous studies $(1,14,19,20)$.

In conclusion, baseline sarcopenia was not associated with survival outcomes, while the development of muscle loss during chemotherapy independently predicted poor TTF and OS among patients with mGC. To the best of our knowledge, ours is the first study to identify the relationships between sarcopenia, muscle loss during treatment, and outcomes among patients with mGC who received chemotherapy.

\section{Conflicts of Interest}

The Authors have no conflict of interest to declare with regard to this study.

\section{Acknowledgements}

The Authors thank Editage (www.editage.jp) for English language editing. The Authors also thank the radiological technologists of the Department of Diagnostic and Interventional Radiology, Aichi Cancer Hospital, for measuring skeletal muscle volume using the CT data.

This research did not receive any specific grant from funding agencies in the public, commercial, or not-for-profit sectors.

\section{References}

1 Ferlay J, Soerjomataram I, Dikshit R, Eser S, Mathers C, Rebelo M, Parkin DM, Forman D and Bray F: Cancer incidence and mortality worldwide: sources, methods and major patterns in GLOBOCAN 2012. Int J Cancer 136: E359-386, 2015.

2 Yamada Y, Higuchi K, Nishikawa K, Gotoh M, Fuse N, Sugimoto N, Nishina T, Amagai K, Chin K, Niwa Y, Tsuji A, Imamura $H$, Tsuda $M$, Yasui $H$, Fujii $H$, Yamaguchi $K$, Yasui $H$, Hironaka S, Shimada K, Miwa H, Hamada C and Hyodo I: Phase III study comparing oxaliplatin plus S-1 with cisplatin plus S-1 in chemotherapy-naive patients with advanced gastric cancer. Ann Oncol 26: 141-148, 2015.

3 Cunningham D, Starling N, Rao S, Iveson T, Nicolson M, Coxon F, Middleton G, Daniel F, Oates J and Norman AR; Upper
Gastrointestinal Clinical Studies Group of the National Cancer Research Institute of the United Kingdom: Capecitabine and oxaliplatin for advanced esophagogastric cancer. N Engl J Med 358: 36-46, 2008.

4 Argilés JM, Busquets S, Stemmler B and López-Soriano FJ: Cancer cachexia: Understanding the molecular basis. Nat Rev Cancer 14: 754-762, 2014.

5 Ongaro E, Buoro V, Cinausero M, Caccialanza R, Turri A, Fanotto V, Basile D, Vitale MG, Ermacora P, Cardellino GG, Nicoletti L, Fornaro L, Casadei-Gardini A and Aprile G: Sarcopenia in gastric cancer: When the loss costs too much. Gastric Cancer 20: 563-572, 2017.

6 Kitagawa M, Haji S and Amagai T: Elevated serum AA/EPA ratio as a predictor of skeletal muscle depletion in cachexic patients with advanced gastro-intestinal cancers. In Vivo 31: 1003-1009, 2017.

7 Prado CM, Baracos VE, McCargar LJ, Mourtzakis M, Mulder KE, Reiman T, Butts CA, Scarfe AG and Sawyer MB: Body composition as an independent determinant of 5-fluorouracilbased chemotherapy toxicity. Clin Cancer Res 13: 3264-3268, 2007.

8 Barret M, Antoun S, Dalban C, Malka D, Mansourbakht T, Zaanan A, Latko E and Taieb J: Sarcopenia is linked to treatment toxicity in patients with metastatic colorectal cancer. Nutr Cancer 66: 583-589, 2014.

9 Zhuang CL, Huang DD, Pang WY, Zhou CJ, Wang SL, Lou N, Ma LL, Yu Z and Shen X: Sarcopenia is an independent predictor of severe postoperative complications and long-term survival after radical gastrectomy for gastric cancer: Analysis from a large-scale cohort. Medicine 95: e3164, 2016.

10 Miyamoto Y, Baba Y, Sakamoto Y, Ohuchi M, Tokunaga R, Kurashige J, Hiyoshi Y, Iwagami S, Yoshida N, Yoshida M, Watanabe $\mathrm{M}$ and Baba $\mathrm{H}$ : Sarcopenia is a negative prognostic factor after curative resection of colorectal cancer. Ann Surg Oncol 22: 2663-2668, 2015.

11 Iritani S, Imai $\mathrm{K}$, Takai $\mathrm{K}$, Hanai $\mathrm{T}$, Ideta $\mathrm{T}$, Miyazaki $\mathrm{T}$, Suetsugu A, Shiraki M, Shimizu M and Moriwaki H: Skeletal muscle depletion is an independent prognostic factor for hepatocellular carcinoma. J Gastroenterol 50: 323-332, 2015.

12 Miyata H, Sugimura K, Motoori M, Fujiwara Y, Omori T, Yanagimoto Y, Ohue M, Yasui M, Miyoshi N, Tomokuni A, Akita $\mathrm{H}$, Kobayashi S, Takahashi $\mathrm{H}$ and Yano M: Clinical assessment of sarcopenia and changes in body composition during neoadjuvant chemotherapy for esophageal cancer. Anticancer Res 37: 3053-3059, 2017.

13 Miyamoto Y, Baba Y, Sakamoto Y, Ohuchi M, Tokunaga R, Kurashige J, Hiyoshi Y, Iwagami S, Yoshida N, Watanabe M and Baba H: Negative impact of skeletal muscle loss after systemic chemotherapy in patients with unresectable colorectal cancer. PLoS One 10: e0129742, 2015.

14 Blauwhoff-Buskermolen S, Versteeg KS, de van der Schueren MA, den Braver NR, Berkhof J, Langius JA and Verheul HM: Loss of muscle mass during chemotherapy is predictive for poor survival of patients with metastatic colorectal cancer. J Clin Oncol 34: 1339-1344, 2016.

15 Chau I, Norman AR, Cunningham D, Waters JS, Oates J and Ross PJ: Multivariate prognostic factor analysis in locally advanced and metastatic esophago-gastric cancer--pooled analysis from three multicenter, randomized, controlled trials using individual patient data. J Clin Oncol 22: 2395-2403, 2004. 
16 Takahari D, Boku N, Mizusawa J, Takashima A, Yamada Y, Yoshino T, Yamazaki K, Koizumi W, Fukase K, Yamaguchi K, Goto M, Nishina T, Tamura T, Tsuji A and Ohtsu A: Determination of prognostic factors in Japanese patients with advanced gastric cancer using the data from a randomized controlled trial, Japan clinical oncology group 9912. Oncologist 19: 358-366, 2014.

17 Eisenhauer EA, Therasse P, Bogaerts J, Schwartz LH, Sargent D, Ford R, Dancey J, Arbuck S, Gwyther S, Mooney M, Rubinstein L, Shankar L, Dodd L, Kaplan R, Lacombe D and Verweij J: New response evaluation criteria in solid tumours: Revised RECIST guideline (version 1.1). Eur J Cancer 45: 228-247, 2009.

18 Common terminology of adverse events (CTCAE), version 4.0. Available https://www.eortc.be/services/doc/ctc/CTCAE_4.03_2010-0614_QuickReference_5x7.pdf (Accessed on 09 Septmeber 2018).

19 Mohri Y, Tanaka K, Ohi M, Toiyama Y, Yasuda H, Inoue Y, Uchida $\mathrm{K}$ and Kusunoki $\mathrm{M}$ : Inflammation-based prognostic score as a predictor of postoperative gastric cancer recurrence. Anticancer Res 32: 4581-4584, 2012.

20 Mourtzakis M, Prado CM, Lieffers JR, Reiman T, McCargar LJ and Baracos VE: A practical and precise approach to quantification of body composition in cancer patients using computed tomography images acquired during routine care. Appl Physiol Nutr Metab 33: 997-1006, 2008.

21 Prado CM, Lieffers JR, McCargar LJ, Reiman T, Sawyer MB, Martin L and Baracos VE: Prevalence and clinical implications of sarcopenic obesity in patients with solid tumours of the respiratory and gastrointestinal tracts: a population-based study. Lancet Oncol 9: 629-635, 2008.

22 Kanda Y: Investigation of the freely available easy-to-use software 'EZR' for medical statistics. Bone Marrow Transplant 48: 452-458, 2013.

23 Mirkin KA, Luke FE, Gangi A, Pimiento JM, Jeong D, Hollenbeak CS and Wong J: Sarcopenia related to neoadjuvant chemotherapy and perioperative outcomes in resected gastric cancer: A multi-institutional analysis. J Gastrointest Oncol 8: 589-595, 2017.

24 Tegels JJ, Van Vugt JL, Reisinger KW, Hulsewé KW, Hoofwijk AG, Derikx JP and Stoot JH: Sarcopenia is highly prevalent in patients undergoing surgery for gastric cancer but not associated with worse outcomes. J Surg Oncol 112: 403-407, 2015.

25 Loprinzi CL, Kugler JW, Sloan JA, Mailliard JA, Krook JE, Wilwerding MB, Rowland KM Jr., Camoriano JK, Novotny PJ and Christensen BJ: Randomized comparison of megestrol acetate versus dexamethasone versus fluoxymesterone for the treatment of cancer anorexia/cachexia. J Clin Oncol 17: 32993306, 1999.
26 Basaria S, Wahlstrom JT, Dobs AS: Clinical review 138: Anabolic-androgenic steroid therapy in the treatment of chronic diseases. J Clin Endocrinol Metab 86: 5108-5117, 2001.

27 Mantovani G, Macciò A, Madeddu C, Serpe R, Massa E, Dessì M, Panzone F and Contu P: Randomized phase III clinical trial of five different arms of treatment in 332 patients with cancer cachexia. Oncologist 15: 200-211, 2010.

28 Solheim TS, Fearon KC, Blum D and Kaasa S: Non-steroidal anti-inflammatory treatment in cancer cachexia: a systematic literature review. Acta Oncol 52: 6-17, 2013.

29 Wu C, Fernandez SA, Criswell T, Chidiac TA, Guttridge D, Villalona-Calero $\mathrm{M}$ and Bekaii-Saab TS: Disrupting cytokine signaling in pancreatic cancer: A phase I/II study of etanercept in combination with gemcitabine in patients with advanced disease. Pancreas 42: 813-818, 2013.

30 Yennurajalingam S, Willey JS, Palmer JL, Allo J, Del Fabbro E, Cohen EN, Tin S, Reuben JM and Bruera E: The role of thalidomide and placebo for the treatment of cancer-related anorexia-cachexia symptoms: Results of a double-blind placebocontrolled randomized study. J Palliat Med 15: 1059-1064, 2012.

31 Temel JS, Abernethy AP, Currow DC, Friend J, Duus EM, Yan $\mathrm{Y}$ and Fearon KC: Anamorelin in patients with non-small-cell lung cancer and cachexia (ROMANA 1 and ROMANA 2): Results from two randomised, double-blind, phase 3 trials. Lancet Oncol 17: 519-531, 2016.

32 Papanicolaou DA, Ather SN, Zhu H, Zhou Y, Lutkiewicz J, Scott $\mathrm{BB}$ and Chandler J: A phase IIA randomized, placebo-controlled clinical trial to study the efficacy and safety of the selective androgen receptor modulator (SARM), MK-0773 in female participants with sarcopenia. J Nutr Health Aging 17: 533-543, 2013.

33 Dobs AS, Boccia RV, Croot CC, Gabrail NY, Dalton JT, Hancock ML, Johnston MA and Steiner MS: Effects of enobosarm on muscle wasting and physical function in patients with cancer: A double-blind, randomised controlled phase 2 trial. Lancet Oncol 14: 335-345, 2013.
Received August 27, 2018

Revised September 10, 2018 Accepted September 12, 2018 